\title{
No association between LRP5 gene polymorphisms and bone and obesity phenotypes in Chinese male- offspring nuclear families
}

Jin-bo YU, Yao-hua KE, Jin-wei HE, Hao ZHANG, Wei-wei HU, Yun-qiu HU, Miao LI, Yu-juan LIU, Jie-mei GU, Wen-zhen FU, Gao GAO, Hua YUE, Wen-jin XIAO, Zhen-lin ZHANG*

Department of Osteoporosis and Bone Diseases, Metabolic Bone Disease and Genetics Research Unit, The Shanghai Sixth People's Hospital, Shanghai Jiaotong University, Shanghai 200233, China

Aim: To investigate the effect of low-density lipoprotein receptor-related protein 5 (LRP5) gene polymorphisms on bone and obesity phenotypes in young Chinese men.

Methods: A total of 1244 subjects from 411 Chinese nuclear families were genotyped by using the polymerase chain reaction-restriction fragment length polymorphism (PCR-RFLP) technique at the Q89R, N740N, and A1330V sites in the LRP5 gene. Bone mineral density (BMD) in the lumbar spine and the hip, total fat mass and total lean mass were measured using dual-energy $X$-ray absorptiometry. The association between LRP5 gene polymorphisms and peak BMD, body mass index (BMI), total fat mass, total lean mass and percentage of fat mass was assessed using a quantitative transmission disequilibrium test (QTDT).

Results: No significant within-family associations were found between genotypes or haplotypes of the LRP5 gene and peak BMD, BMI, total fat mass, total lean mass and percentage of fat mass. The 1000 permutations that were subsequently simulated were in agreement with these within-family association results.

Conclusion: Our results suggest that common polymorphic variations of the LRP5 gene do not influence peak bone mass acquisition and obesity phenotypes in young Chinese men.

Keywords: LRP5; BMD; fat mass; lean mass; transmission disequilibrium test

Acta Pharmacologica Sinica (2010) 31: 1464-1469; doi: 10.1038/aps.2010.92; published online 18 Oct 2010

\section{Introduction}

Osteoporosis and obesity are two common and complex diseases. Interestingly, the correlation between osteoporosis and obesity has been established both genetically and phenotypically ${ }^{[1-4]}$. In addition, genes associated with osteoporosis may also be candidates for obesity. The low-density lipoprotein receptor-related protein 5 (LRP5) functions as a cell membrane co-receptor for Wnt and plays an important role in the Wnt signaling pathway ${ }^{[5]}$. It is expressed in many tissues, including bone and liver, and it regulates bone and cholesterol metabolism ${ }^{[5-8]}$. From a molecular perspective, the LRP5/ Wnt signaling pathway plays a key role in the switch between osteogenesis and adipogenesis ${ }^{[9,10]}$.

Because LRP5 is a key regulator of osteoblast proliferation and bone formation, loss-of-function mutations of the LRP5

\footnotetext{
* To whom correspondence should be addressed.

E-mail ZZL2002@medmail.com.cn

Received 2010-03-24 Accepted 2010-06-17
}

gene have been associated with osteoporosis-pseudoglioma syndrome (OPPG), an autosomal recessive disorder characterized by low bone mass, spontaneous fractures and blindness ${ }^{[5]}$. In contrast, gain-of-function mutations of the LRP5 gene, such as dominant $\mathrm{G} 171 \mathrm{~V}$, cause high bone mass and increased bone biomechanical properties ${ }^{[11]}$. Because of its crucial role in bone development, common variations such as single nucleotide polymorphisms in the LRP5 gene and their relation to bone phenotypes have been extensively studied. LRP5 polymorphisms have been shown to determine bone mass variation in the general population ${ }^{[12-15]}$.

$L R P 5$, a member of the low-density lipoprotein receptor family, is also important for glucose and cholesterol metabo$\operatorname{lism}^{[7,8]}$. Several studies have found that LRP5 polymorphisms are associated with complex diseases or traits that are related to obesity ${ }^{[16,17]}$. However, only one study has reported the relationship between $L R P 5$ polymorphisms and obesity in Caucasian nuclear families ${ }^{[18]}$.

Therefore, the LRP5 gene could be a pleiotropic genetic fac- 
tor influencing both osteoporosis and obesity phenotypes. However, a clear relationship between LRP5's single nucleotide polymorphisms (SNPs) and peak BMD and obesity phenotypes has not been elucidated, and studies on men are especially lacking. Here, focusing on the well-characterized polymorphisms of the LRP5 gene related to osteoporosis (Q89R, N740N, and A1330V), we investigated the relationship of these polymorphisms with peak BMD, BMI, total fat mass, total lean mass and the percentage of fat mass in Chinese male offspring of nuclear families using a quantitative transmission disequilibrium test (QTDT).

\section{Materials and methods Subjects}

The study was approved by the Ethics Committee of the Shanghai Jiaotong University affiliated Sixth People's Hospital(Shanghai, China). All the subjects involved in the study were selected from the local population of Shanghai City by the Department of Osteoporosis, and they signed informed consent forms before entering the project. We recruited 427 nuclear families from 2004 to 2007. However, only 411 families were analyzed because the genotypes of 15 individuals could not be determined due to poor DNA quality and one family deviated from Mendelian inheritance. These 411 nuclear families were composed of both parents and at least one healthy male child whose age was largely between 20 and 40 years old. The great majority of the families (400) had one child, and 11 families had two children. All the recruited sons were healthy. The following criteria were used to exclude individuals from the study: (1) serious consequences from a cerebral vascular disease; (2) diabetes mellitus; (3) chronic renal disease; (4) serious chronic liver disease or alcoholism; (5) significant chronic lung disease; (6) corticosteroid therapy at pharmacologic levels for more than 6 months; (7) treatment with anticonvulsant therapy for more than 6 months; (8) evidence of other metabolic or inherited bone disease such as hyperparathyroidism or hypoparathyroidism, Paget's disease of bone, osteomalacia and osteogenesis imperfecta; (9) rheumatoid arthritis or collagen disease; (10) a significant disease of any endocrine organ that would affect bone mass; (11) hyperthyroidism; and (12) any neurological or musculoskeletal condition that would cause a nongenetic low bone mass.

\section{Phenotype measurements}

The BMD $\left(\mathrm{g} / \mathrm{cm}^{2}\right)$ of the anteroposterior lumbar spine (L1-4) and the left proximal femur (including the femoral neck, the trochanter and the total hip), the total fat mass and the total lean mass were measured with a dual-energy X-ray absorptiometry densitometer. The coefficient of variation $(\mathrm{CV})$ was obtained from three repeated measurements on 15 individuals. The $C V$ values of the BMD in L1-4, the femoral neck, the trochanter and the total hip were $1.39 \%, 2.22 \%, 1.41 \%, 0.70 \%$, respectively ${ }^{[19]}$. For body composition, the CVs were $3.72 \%$ and $1.18 \%$ for total fat mass and total lean mass, respectively. Height and body weight were measured using standardized equipment. The BMI was defined as the weight/height ${ }^{2}$ in $\mathrm{kg} / \mathrm{m}^{2}$. The percentage of fat mass (PFM) was calculated as the total fat mass divided by weight.

\section{Genotyping}

The DNA was isolated from peripheral blood leukocytes using conventional methods. Polymerase chain reaction (PCR) was performed in the following steps: $95{ }^{\circ} \mathrm{C}$ for $5 \mathrm{~min}$ and then 32 cycles of $95{ }^{\circ} \mathrm{C}$ for $30 \mathrm{~s}, 65^{\circ} \mathrm{C}$ for $30 \mathrm{~s}, 72{ }^{\circ} \mathrm{C}$ for $45 \mathrm{~s}$, and finally $72{ }^{\circ} \mathrm{C}$ for $5 \mathrm{~min}$ (Okubo et $\mathrm{al}^{[20]}$ ). The PCR primers and the restriction endonucleases used for genotyping are summarized in Table 1. The PCR products were digested with Ava II, Ase I and Dra III restriction endonucleases, respectively. The Q89R genotypes (c.314A>G) were separated by electrophoresis in a $2 \%$ agarose gel. The AA genotype produces a 436-bp fragment, the GG genotype produces two fragments of $274 \mathrm{bp}$ and $162 \mathrm{bp}$, and the heterozygous AG genotype produces three fragments of $436 \mathrm{bp}, 274 \mathrm{bp}$, and $162 \mathrm{bp}$. The N740N (c.2268T>C) and A1330V (c.4037C>T) genotypes were separated by electrophoresis in a $12 \%$ polyacrylamide gel. The N740N CC genotype produces a 237-bp fragment, the TT genotype produces two fragments of $216 \mathrm{bp}$ and $21 \mathrm{bp}$, and the heterozygous CT genotype produces three fragments of $237 \mathrm{bp}, 216 \mathrm{bp}$, and $21 \mathrm{bp}$. The A1330V CC genotype produces a 143-bp fragment, the TT genotype produces two fragments of $119 \mathrm{bp}$ and $24 \mathrm{bp}$, and the heterozygous CT genotype produces three fragments of $143 \mathrm{bp}, 119 \mathrm{bp}$, and $24 \mathrm{bp}{ }^{[15]}$.

\section{Statistical analysis}

A Chi-square test assessed if the genotype frequencies of every

Table 1. Information of the analyzed LRP5 SNPs in this study.

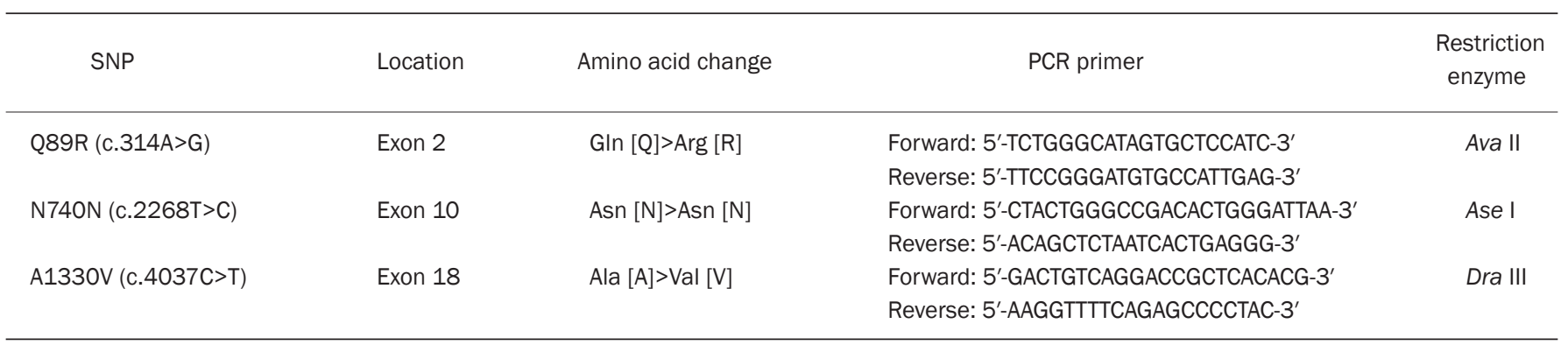


SNP were in Hardy-Weinberg equilibrium. The ShapiroWilks test and the Bartlett test were used to assess if the variables of BMD, BMI, fat mass and lean mass had a normal distribution and to test the homogeneity of variances within each of the three SNPs genotypes. Haplotypes were constructed from the three common SNPs in LRP5 using Phase software version 2.0.2 $2^{[21]}$. We examined the Lewontin D and linkage disequilibrium (LD) coefficient $r^{2}$ between all pairs of biallelic loci using Haploview version 3.2 $2^{[22]}$. The QTDT was used to measure the population stratification, total association and within-family association between SNPs and BMD and obesity phenotypes. The QTDT software package is available on the Internet (http://www.sph.umich.edu/csg/abecasis/QTDT/). As indicated by Abecasis et $a l^{[23]}$, total association effects are partitioned into between- and within-family components. The between-family component of association is specific to each nuclear family and could be influenced by population stratification. The within-family association tests are immune to the stratification of the population and, therefore, they are significant only in the presence of linkage disequilibrium. Because all of the children in our nuclear families were sons and the effects of the parents' phenotypes were excluded in the QTDT, sex was not used as a covariate to adjust the sons' bone and obesity phenotypic values. Raw BMD values were adjusted by age, height and weight as covariates. BMI, total fat mass, total lean mass and percentage of fat mass values were adjusted by age as a covariate. Because false-positive results might be generated in multiple tests, 1000 simulations were performed to generate empirical $P$ values ${ }^{[2]}$ to assess the reliability of the results. The significance level was set at $P<0.05$ for all the analyses. The statistical analyses were conducted using SPSS package version 11.5.

\section{Results}

\section{The distribution of genotype and haplotype}

A total of 1244 individuals from 411 nuclear families comprising 822 parents and 422 offspring were recruited. The basic characteristics of the study subjects are summarized in Table 2. Parental total fat mass and total lean mass were not obtained. All the study subjects were men with an average age of $30.6 \pm 6.3$ (mean \pm SD) years. The three SNP genotypes and allele frequencies in the son group are presented in Table 3. All SNPs had a minor allele frequency (MAF) greater than $10 \%$ in our population, and the genotype frequencies of these SNPs did not deviate from the Hardy-Weinberg equilibrium. Each pair of biallelic SNPs had intermediate values of LD $\left(0.432<\mathrm{D}^{\prime}<0.729,0.109<r^{2}<0.510\right)$. The most common haplotype was ACC, which had a frequency of $72.3 \%$. The characteristics of the 411 unrelated sons were classified according to the three SNP genotypes and are summarized in Table 4 . All the raw phenotypic values of the son group followed a normal distribution. The genotype data of each family were verified for Mendelian inheritance.

Association between SNPs in the LRP5 gene and peak BMD There were 127, 212, and 223 informative nuclear families
Table 2. Basic characteristics of parents and son groups (mean \pm SD).

\begin{tabular}{|c|c|c|c|}
\hline & $\begin{array}{l}\text { Father } \\
(n=411)\end{array}$ & $\begin{array}{l}\text { Mother } \\
(n=411)\end{array}$ & $\begin{array}{l}\text { Son } \\
(n=422)\end{array}$ \\
\hline Age (years) & $61.1 \pm 7.0$ & $58.2 \pm 6.3$ & $30.6 \pm 6.3$ \\
\hline Height (cm) & $167.9 \pm 5.9$ & $155.8 \pm 5.4$ & $173.0 \pm 6.0$ \\
\hline Weight (kg) & $69.9 \pm 9.4$ & $58.3 \pm 8.1$ & $71.1 \pm 11.1$ \\
\hline $\mathrm{BMI}\left(\mathrm{kg} / \mathrm{m}^{2}\right)$ & $24.8 \pm 3.1$ & $24.0 \pm 3.1$ & $23.7 \pm 3.4$ \\
\hline L1-4 (g/ $\left.\mathrm{cm}^{2}\right)$ & $1.142 \pm 0.173$ & $0.995 \pm 0.172$ & $1.139 \pm 0.137$ \\
\hline $\begin{array}{l}\text { Femoral neck BMD } \\
\left(\mathrm{g} / \mathrm{cm}^{2}\right)\end{array}$ & $0.893 \pm 0.131$ & $0.801 \pm 0.144$ & $0.998 \pm 0.144$ \\
\hline $\begin{array}{l}\text { Trochanter BMD } \\
\left(\mathrm{g} / \mathrm{cm}^{2}\right)\end{array}$ & $0.819 \pm 0.141$ & $0.692 \pm 0.149$ & $0.825 \pm 0.147$ \\
\hline Total hip BMD $\left(\mathrm{g} / \mathrm{cm}^{2}\right)$ & $0.969 \pm 0.129$ & $0.872 \pm 0.149$ & $1.016 \pm 0.139$ \\
\hline Total fat mass (kg) & - & - & $16.0 \pm 7.0$ \\
\hline Total lean mass (kg) & - & - & $51.4 \pm 5.8$ \\
\hline PFM (\%) & - & - & $21.9 \pm 7$ \\
\hline
\end{tabular}

Table 3. The three SNPs genotypes and allele frequencies in unrelated son group $(n=411)$.

\begin{tabular}{llllll}
\hline $\begin{array}{l}\text { Polymor- } \\
\text { phism }\end{array}$ & \multicolumn{2}{c}{ Genotype frequencies } & & \multicolumn{2}{c}{$\begin{array}{c}\text { Allele } \\
\text { frequencies }\end{array}$} \\
\hline Q89R & AA & AG & GG & A & G \\
& $325(79.1 \%)$ & $81(19.7 \%)$ & $5(1.2 \%)$ & 0.889 & 0.111 \\
N740N & CC & CT & TT & C & T \\
& $279(67.9 \%)$ & $121(29.4 \%)$ & $11(2.7 \%)$ & 0.826 & 0.174 \\
A1330V & CC & CT & TT & C & T \\
& $271(65.9 \%)$ & $126(30.7 \%)$ & $14(3.4 \%)$ & 0.813 & 0.187 \\
\hline
\end{tabular}

for the QTDT analyses of the Q89R, N740N and A1330V sites, respectively, and each of those families had at least one heterozygous parent. The results of the QTDT analysis are presented in Table 5. No significant population stratification was found for BMD at any bone site. Regarding the total association, N740N was significantly associated with BMD at the total hip, and A1330V was significantly associated with BMD at L1-4, the femoral neck and the total hip. However, we did not find significant associations between SNPS in LRP5 and peak BMD at any bone site for the within-family data. The 1000 permutations were in agreement with these within-family association results for all the tested parameters. Furthermore, we observed an association between the most common haplotype (ACC) and peak BMD using QTDT. There were 272 informative nuclear families for the QTDT analysis at haplotype ACC. None of the tests for population stratification, total association and within-family association between haplotype ACC and peak BMD were significant.

\section{Association between SNPs in LRP5 and obesity}

The results of the QTDT analysis are presented in Table 6. No population stratification was identified for BMI, total fat mass, total lean mass and percentage of fat mass. Regarding 
Table 4. Characteristics of the sons $(n=422)$ classified according to the three SNPs genotypes.

\begin{tabular}{|c|c|c|c|c|c|c|c|c|c|}
\hline & \multicolumn{3}{|c|}{ Q89R } & \multicolumn{3}{|c|}{ N740N } & \multicolumn{3}{|c|}{ A1330V } \\
\hline & $\mathrm{AA}$ & $A G$ & GG & $\mathrm{CC}$ & CT & $\mathrm{TT}$ & $\mathrm{CC}$ & CT & $\mathrm{TT}$ \\
\hline$n$ & 334 & 83 & 5 & 287 & 124 & 11 & 279 & 129 & 14 \\
\hline Age (years) & $30.5 \pm 5.8$ & $30.9 \pm 6.4$ & $32.4 \pm 8.8$ & $30.3 \pm 5.9$ & $31.4 \pm 6.0$ & $28.9 \pm 5.3$ & $30.2 \pm 5.9$ & $31.4 \pm 5.8$ & $30.1 \pm 7.0$ \\
\hline Height (cm) & $173.0 \pm 6.1$ & $172.6 \pm 5.1$ & $172.4 \pm 6.0$ & $172.7 \pm 6.0$ & $173.6 \pm 5.6$ & $171.5 \pm 5.6$ & $172.7 \pm 6.1$ & $173.5 \pm 5.6$ & $172.9 \pm 4.8$ \\
\hline Weight (kg) & $71.1 \pm 11.0$ & $69.5 \pm 10.7$ & $70.1 \pm 10.3$ & $70.9 \pm 11.0$ & $71.0 \pm 11.0$ & $66.2 \pm 8.5$ & $70.5 \pm 10.9$ & $71.7 \pm 11.3$ & $68.5 \pm 8.7$ \\
\hline $\mathrm{BMI}\left(\mathrm{kg} / \mathrm{m}^{2}\right)$ & $23.8 \pm 3.4$ & $23.3 \pm 3.4$ & $23.8 \pm 5.0$ & $23.8 \pm 3.4$ & $23.5 \pm 3.4$ & $22.5 \pm 2.9$ & $23.7 \pm 3.4$ & $23.8 \pm 3.5$ & $23.0 \pm 3.0$ \\
\hline $\begin{array}{l}\text { L1-4 BMD } \\
\left(\mathrm{g} / \mathrm{cm}^{2}\right)\end{array}$ & $1.140 \pm 0.138$ & $1.127 \pm 0.138$ & $1.173 \pm 0.039$ & $1.142 \pm 0.137$ & $1.132 \pm 0.142$ & $1.090 \pm 0.095$ & $1.140 \pm 0.136$ & $1.136 \pm 0.144$ & $1.112 \pm 0.114$ \\
\hline $\begin{array}{l}\text { Neck BMD } \\
\left(\mathrm{g} / \mathrm{cm}^{2}\right)\end{array}$ & $1.002 \pm 0.139$ & $0.980 \pm 0.161$ & $1.052 \pm 0.115$ & $1.004 \pm 0.140$ & $0.991 \pm 0.154$ & $0.940 \pm 0.090$ & $1.006 \pm 0.143$ & $0.984 \pm 0.149$ & $0.971 \pm 0.085$ \\
\hline $\begin{array}{l}\text { Trochanter } \\
\text { BMD }\left(\mathrm{g} / \mathrm{cm}^{2}\right)\end{array}$ & $0.823 \pm 0.142$ & $0.814 \pm 0.152$ & $0.816 \pm 0.102$ & $0.826 \pm 0.137$ & $0.816 \pm 0.162$ & $0.760 \pm 0.072$ & $0.824 \pm 0.139$ & $0.819 \pm 0.160$ & $0.788 \pm 0.086$ \\
\hline $\begin{array}{l}\text { Total hip } \\
\text { BMD }\left(\mathrm{g} / \mathrm{cm}^{2}\right)\end{array}$ & $1.017 \pm 0.134$ & $1.002 \pm 0.154$ & $1.066 \pm 0.113$ & $1.024 \pm 0.137$ & $1.000 \pm 0.142$ & $0.960 \pm 0.088$ & $1.022 \pm 0.138$ & $1.001 \pm 0.140$ & $0.984 \pm 0.092$ \\
\hline $\begin{array}{l}\text { Total fat } \\
\text { mass (kg) }\end{array}$ & $16.1 \pm 7.1$ & $15.3 \pm 6.0$ & $13.3 \pm 7.4$ & $15.8 \pm 6.9$ & $16.4 \pm 6.9$ & $13.0 \pm 5.9$ & $15.6 \pm 6.9$ & $16.6 \pm 7.1$ & $15.3 \pm 5.7$ \\
\hline $\begin{array}{l}\text { Total lean } \\
\text { mass (kg) }\end{array}$ & $51.5 \pm 5.5$ & $50.6 \pm 5.9$ & $51.8 \pm 8.1$ & $51.4 \pm 5.4$ & $51.6 \pm 6.0$ & $47.9 \pm 3.2$ & $51.2 \pm 5.6$ & $51.8 \pm 5.8$ & $49.8 \pm 4.0$ \\
\hline PFM(\%) & $22.0 \pm 7$ & $21.5 \pm 7$ & $18.4 \pm 8$ & $21.8 \pm 7$ & $22.3 \pm 7$ & $19.7 \pm 7$ & $21.6 \pm 7$ & $22.4 \pm 7$ & $21.8 \pm 6$ \\
\hline
\end{tabular}

Table 5. $P$ value of tests for population stratification, total association, and within-family association between LRP5 SNPs and peak BMD. Bold indicates significant $P$ value. BMD values were adjusted by age, height and weight as covariates.

\begin{tabular}{lccc}
\hline & Q89R & N740N & A1330V \\
\hline \multicolumn{4}{l}{ Tests of population stratification } \\
L1-4 BMD & 0.0711 & 0.4160 & \\
Femoral neck BMD & 0.8255 & 0.2695 & 0.4438 \\
Trochant er BMD & 0.0590 & 0.2141 & 0.4719 \\
Total hip BMD & 0.1585 & 0.2111 & 0.4345 \\
& & & \\
Tests of total association & & & \\
L1-4 BMD & 0.2093 & 0.2629 & 0.0170 \\
Femoral neck BMD & 0.1443 & 0.2668 & 0.0227 \\
Trochanter BMD & 0.8298 & 0.1669 & 0.0566 \\
Total hip BMD & 0.3663 & 0.0471 & 0.0162 \\
& & & \\
Tests of within-family association & & \\
L1-4 BMD & 0.2782 & 0.8628 & 0.5468 \\
Femoral neck BMD & 0.4148 & 0.6528 & 0.3853 \\
Trochanter BMD & 0.0656 & 0.7239 & 0.6944 \\
Total hip BMD & 0.3803 & 0.9189 & 0.5943 \\
& & & \\
P 1000 permutation of within-family association & \\
L1-4 BMD & 0.1950 & 0.8440 & 0.5270 \\
Femoral neck BMD & 0.4350 & 0.6330 & 0.3430 \\
Trochanter BMD & 0.0750 & 0.6890 & 0.6880 \\
Total hip BMD & 0.3900 & 0.9160 & 0.5630 \\
\hline
\end{tabular}

Table 6. $P$ value of tests for population stratification, total association, and within-family association between LRP5 SNPs and obesity phenotypes. $\mathrm{BMI}$, total fat mass, total lean mass and PFM values were adjusted by age as a covariate.

\begin{tabular}{|c|c|c|c|}
\hline & Q89R & N740N & A1330V \\
\hline \multicolumn{4}{|c|}{ Tests of population stratification } \\
\hline BMI & 0.4588 & 0.8774 & 0.3393 \\
\hline Fat mass & 0.6145 & 0.5621 & 0.5837 \\
\hline Lean mass & 0.2699 & 0.7653 & 0.8126 \\
\hline PFM & 0.5204 & 0.7361 & 0.5028 \\
\hline \multicolumn{4}{|c|}{ Tests of total association } \\
\hline BMI & 0.2141 & 0.3195 & 0.8180 \\
\hline Fat mass & 0.1876 & 0.8340 & 0.2456 \\
\hline Lean mass & 0.6004 & 0.6035 & 0.7569 \\
\hline PFM & 0.3762 & 0.7813 & 0.5047 \\
\hline \multicolumn{4}{|c|}{ Tests of within-family association } \\
\hline BMI & 0.8871 & 0.5397 & 0.4746 \\
\hline Fat mass & 0.6754 & 0.7736 & 0.2276 \\
\hline Lean mass & 0.5868 & 0.5691 & 0.9509 \\
\hline PFM & 0.9643 & 0.9511 & 0.3444 \\
\hline \multicolumn{4}{|c|}{$P 1000$ permutation of within-family association } \\
\hline BMI & 0.8730 & 0.5470 & 0.5010 \\
\hline Fat mass & 0.7590 & 0.8350 & 0.3630 \\
\hline Lean mass & 0.6640 & 0.6420 & 0.9730 \\
\hline PFM & 0.9750 & 0.9570 & 0.3770 \\
\hline
\end{tabular}

the obesity phenotypes, no significant total association and within-family association was detected. The subsequent 1000 permutation tests confirmed these negative within-family association results. In addition, we also investigated the 
association between the most common haplotype (ACC) and obesity phenotypes using QTDT. No significant population stratification, total association and within-family association were found between haplotype ACC and BMI, total fat mass, total lean mass and percentage of fat mass.

\section{Discussion}

A number of studies have investigated the association between LRP5 polymorphisms and BMD, revealing inconsistent results. Most of the association studies used the traditional association approach in a random population. The regular association approach may yield spurious results due to population stratification. In addition, the linkage approach is often short on statistical power with the currently used sample sizes. The TDT, a family-based association approach, is immune to population stratification and is more powerful when compared with the traditional linkage approach. The TDT has been proposed by Spielman et $a l^{[25]}$ and, when extended to quantitative traits ${ }^{[26]}$, can be used in nuclear families with or without parental phenotypes.

The LRP5 cooperates with members of the frizzled family of seven-pass transmembrane receptors to bind Wnt proteins and forms a functional ligand-receptor complex that activates the canonical $W n t / \beta$-catenin pathway. The LRP5/Wnt signaling pathway is important for osteoblast differentiation, and mutations in the YWTD/EGF domains of the LRP5 gene are associated with low bone mass syndromes. Numerous studies have revealed the association of exonic and intronic SNPs of LRP5 with BMD variation. Most of the studies that test these associations have been performed in old women; few studies have investigated the relationship between LRP5 gene polymorphisms and peak BMD variation in young men. Koh et $a{ }^{[27]}$ reported that the Q89R polymorphism was significantly associated with BMD in the femoral neck in 219 young Korean men. After adjusting for age, weight and height, a marginal association was observed in the femoral neck $(P=0.098)$. No statistically significant relationship was found between the A1330V polymorphism and BMD in the lumbar spine or the hip. In another study, the polymorphic valine variant at position A1330V of the LRP5 gene was significantly associated with reduced bone mineral content (BMC) and BMD values in healthy young Finnish men ${ }^{[28]}$. The Gothenburg Osteoporosis and Obesity Determinants (GOOD) Study ( $n=1068$ aged 18-20 years) showed no association between the A1330V genotype and bone phenotypes in men $^{[14]}$. In the present study, after adjusting for the covariates of age, height and weight, we failed to find significant associations between Q89R, N740N, and $\mathrm{A} 1330 \mathrm{~V}$ in the LRP5 gene and peak BMD variation in young Chinese men. Our results did not provide evidence to suggest that Q89R, N740N, and A1330V were quantitative trait loci (QTLs) or were in strong disequilibrium with a QTL underlying spine and hip BMD variation in young Chinese men. Our previous study found that Q89R and N740N were significantly associated with BMD in the femoral neck in postmenopausal Chinese women ${ }^{[15]}$. Sex-specific factors might be related to the action of $L R P 5$ on BMD.
Although the importance of the LRP5 gene to bone biology is widely acknowledged, its importance to obesity has seldom been reported. Fujino et al ${ }^{[7]}$ found that LRP5 was required for cholesterol and glucose metabolism. Guo et al ${ }^{[18]}$ reported a significant association between SNPs and haplotypes in the LRP5 gene and human obesity, but the associations observed were found mainly in women. We measured whole-body fat mass, lean mass and BMI as indices of the degree of obesity. Our study did not find a significant association between LRP5 polymorphisms and obesity in young Chinese men. These results seem to agree with Guo et al ${ }^{[18]}$.

Our study has several limitations. We investigated only three common polymorphisms in the LRP5 gene. We cannot rule out the possibility that an association may exist between other polymorphisms in the LRP5 gene and bone and obesity phenotypes. Despite the relatively large number of nuclear families (411), we tested only the most common haplotype (ACC) in the haplotype analyses because a limited number of subjects had the other haplotypes.

Our study also has some strengths. First, we selected young men aged between 20 to 40 years because they were expected to have reached their peak BMD. Second, we measured total fat mass and total lean mass as indices of obesity. Third, we investigated the relationship between LRP5 gene polymorphisms and peak BMD and obesity phenotypes in 411 male offspring of nuclear families using QTDT. Due to our large sample size, the power to test a candidate gene as a QTL was greater than $80 \%$, which can explain about $10 \%$ of the variation in BMD and obesity phenotypes.

In summary, we failed to find a significant association between three common polymorphisms in the LRP5 gene and peak BMD and obesity phenotypes in young Chinese men. Further studies with denser markers and larger sample sizes might shed light on the role of the LRP5 gene in osteoporosis and obesity.

\section{Acknowledgements}

This study was supported by the National Natural Science Foundation of China (№ 30570891, 30771019, and 30800387) and the Program of Shanghai Chief Scientist (No 08XD1403000).

\section{Author contribution}

Zhen-lin ZHANG designed research; Jin-bo YU, Hao ZHANG, Wei-wei HU, Yu-juan LIU, Jie-mei GU recruited research subjects; Yun-qiu HU, Miao LI measured BMD, total fat mass and total lean mass; Jin-bo YU, Jin-wei HE, Wen-zhen FU,Yao-hua KE, Gao GAO, Hua YUE, Wen-jin XIAO performed research; Zhen-lin ZHANG contributed new analytic tools; Jin-bo YU, Zhen-lin ZHANG analyzed data; Jin-bo YU wrote the paper.

\section{References}

1 Coin A, Sergi G, Benincà P, Lupoli L, Cinti G, Ferrara L, et al. Bone mineral density and body composition in underweight and normal elderly subjects. Osteoporos Int 2000; 11: 1043-50.

2 Tóth E, Ferenc V, Mészáros S, Csupor E, Horváth C. Effects of body 
mass index on bone mineral density in men. Orv Hetil 2005; 146: 1489-93.

3 Bustamante M, Nogués X, Mellibovsky L, Agueda L, Jurado S, Cáceres $\mathrm{E}$, et al. Polymorphisms in the interleukin- 6 receptor gene are associated with bone mineral density and body mass index in Spanish postmenopausal women. Eur J Endocrinol 2007; 157: 677-84.

4 Li H, Xie H, Liu W, Hu R, Huang B, Tan YF, et al. A novel microRNA targeting HDAC5 regulates osteoblast differentiation in mice and contributes to primary osteoporosis in humans. J Clin Invest 2009; 119: 3666-77.

5 Gong Y, Slee RB, Fukai N, Rawadi G, Roman-Roman S, Reginato AM, et al. LDL receptor-related protein 5 (LRP5) affects bone accrual and eye development. Cell 2001; 107: 513-23.

6 Little RD, Carulli JP, Del Mastro RG, Dupuis J, Osborne M, Folz C, et al. A mutation in the LDL receptor-related protein 5 gene results in the autosomal dominant high-bone-mass trait. Am J Hum Genet 2002; 70: 11-9.

7 Fujino T, Asaba H, Kang MJ, Ikeda Y, Sone H, Takada S, et al. Lowdensity lipoprotein receptor-related protein 5 (LRP5) is essential for normal cholesterol metabolism and glucose-induced insulin secretion. Proc Natl Acad Sci USA 2003; 100: 229-34.

8 Jin T. The WNT signaling pathway and diabetes mellitus. Diabetologia 2008; 51: 1771-80.

9 Bennett CN, Ross SE, Longo KA, Bajnok L, Hemati N, Johnson KW, et al. Regulation of Wnt signaling during adipogenesis. J Biol Chem 2002; 277: 30998-1004.

10 Ross SE, Hemati N, Longo KA, Bennett CN, Lucas PC, Erickson RL, et al. Inhibition of adipogenesis by Wnt signaling. Science 2000; 289: 950-3.

11 Boyden LM, Mao J, Belsky J, Mitzner L, Farhi A, Mitnick MA, et al. High bone density due to a mutation in LDL-receptor-related protein $5 . \mathrm{N}$ Engl J Med 2002; 346: 1513-21.

12 Lee YH, Woo JH, Choi SJ, Ji JD, Song GG. Association between the A1330V polymorphism of the low-density lipoprotein receptor-related protein 5 gene and bone mineral density: a meta-analysis. Rheumatol Int 2009; 29: 539-44.

13 Tran BN, Nguyen ND, Eisman JA, Nguyen TV. Association between LRP5 polymorphism and bone mineral density: a Bayesian metaanalysis. BMC Med Genet 2008; 9: 55.

14 Grundberg E, Lau EM, Lorentzson M, Karlsson M, Holmberg A, Groop $\mathrm{L}$, et al. Large-scale association study between two coding LRP5 gene polymorphisms and bone phenotypes and fractures in men. Osteoporos Int 2008; 19: 829-37.

15 Zhang ZL, Qin YJ, He JW, Huang QR, Li M, Hu YQ, et al. Association of polymorphisms in low-density lipoprotein receptor-related protein 5 gene with bone mineral density in postmenopausal Chinese women. Acta Pharmacol Sin 2005; 26: 1111-6.

16 Figueroa DJ, Hess JF, Ky B, Brown SD, Sandig V, Hermanowski-Vosatka $A$, et al. Expression of the type I diabetes-associated gene LRP5 in macrophages, vitamin A system cells, and the Islets of Langerhans suggests multiple potential roles in diabetes. J Histochem Cytochem 2000; 48: 1357-68.

17 Bruford EA, Riise R, Teague PW, Porter K, Thomson KL, Moore AT, et al. Linkage mapping in 29 Bardet-Biedl syndrome families confirms loci in chromosomal regions $11 q 13,15 q 22.3-q 23$, and $16 q 21$. Genomics 1997; 41: 93-9.

18 Guo YF, Xiong DH, Shen H, Zhao LJ, Xiao P, Guo Y, et al. Polymorphisms of the low-density lipoprotein receptor-related protein 5 (LRP5) gene are associated with obesity phenotypes in a large family-based association study. J Med Genet 2006; 43: 798-803.

19 Gao G, Zhang ZL, Zhang H, Hu WW, Huang QR, Lu JH, et al. Hip axis length changes in 10554 males and females and the association with femoral neck fracture. J Clin Densitom 2008; 11: 360-6

20 Okubo M, Horinishi A, Kim DH, Yamamoto TT, Murase T. Seven novel sequence variants in the human low density lipoprotein receptor related protein 5 (LRP5) gene. Hum Mutat 2002; 19: 186.

21 Stephens M, Smith NJ, Donnelly P. A new statistical method for haplotype reconstruction from population data. Am J Hum Genet 2001; 68: 978-89

22 Barrett JC, Fry B, Maller J, Daly MJ. Haploviw: analysis and visualization of LD and haplotype maps. Bioinformatics 2005; 21: 263-5

23 Abecasis GR, Cardon LR, Cookson WO. A general test of association for quantitative traits in nuclear families. Am J Hum Genet 2000; 66: 279-92.

24 Zhang ZL, He JW, Qin YJ, Hu YQ, Li M, Zhang H, et al. Association between myostatin gene polymorphisms and peak BMD variation in Chinese nuclear families. Osteoporos Int 2008; 19: 39-47.

25 Spielman RS, McGinnis RE, Ewens WJ. Transmission test for linkage disequilibrium: the insulin gene region and insulin-dependent diabetes mellitus (IDDM). Am J Hum Genet 1993; 52: 506-16.

26 Allison DB. Transmission-disequilibrium tests for quantitative traits. Am J Hum Genet 1997; 60: 676-90.

27 Koh JM, Jung MH, Hong JS, Park HJ, Chang JS, Shin HD, et al. Association between bone mineral density and LDL receptor-related protein 5 gene polymorphisms in young Korean men. J Korean Med Sci 2004; 19: 407-12.

28 Saarinen A, Välimäki VV, Välimäki MJ, Löyttyniemi E, Auro K, Uusen $\mathrm{P}$, et al. The A1330V polymorphism of the low-density lipoprotein receptor-related protein 5 gene (LRP5) associates with low peak bone mass in young healthy men. Bone 2007; 40: 1006-12. 